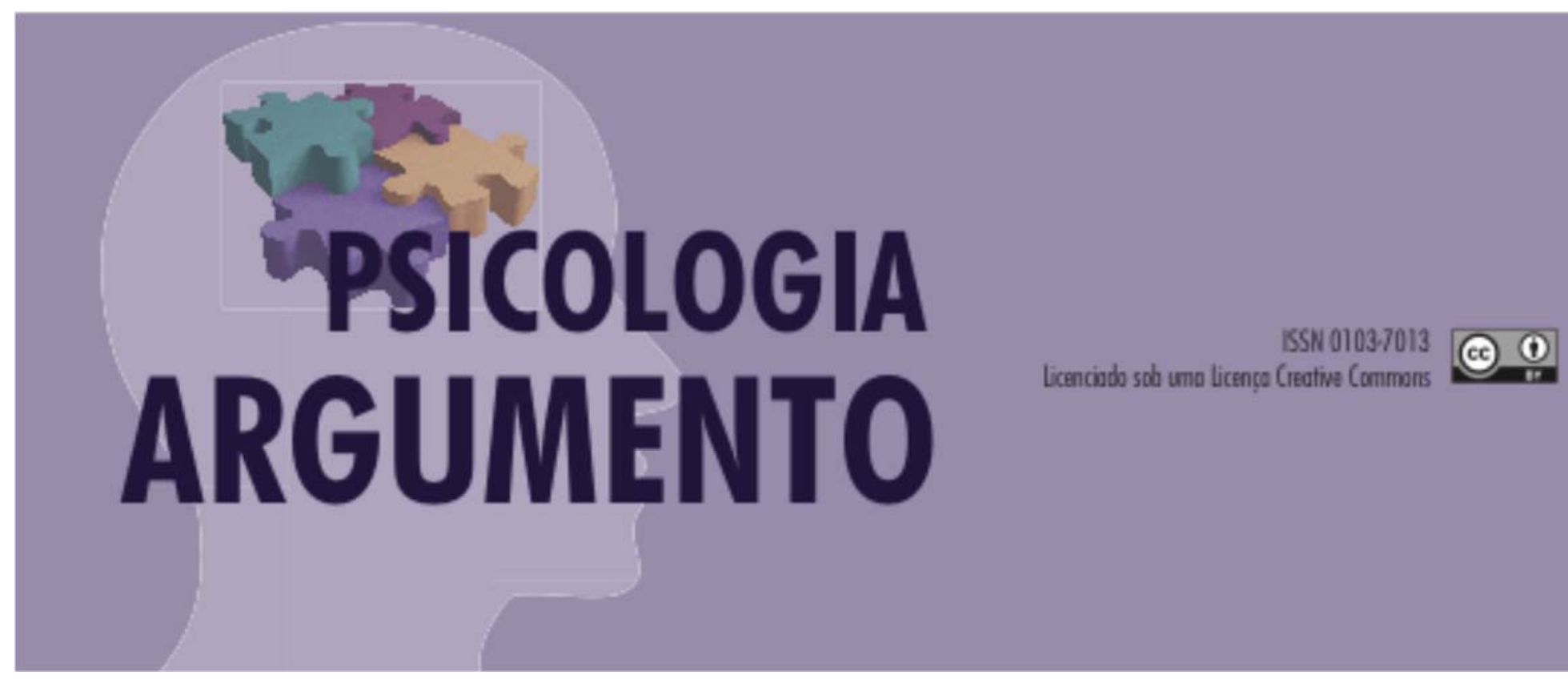

doi: http://dx.doi.org/10.7213/psicolargum.36.94.AO03

\title{
Vivências e sociabilidades: lazer e tempo livre de adolescentes de escolas públicas e particulares
}

\section{Experiences and sociability: leisure and free time of young people from public and private schools}

Manoela Pagotto Martins Nodari

Doutoranda - Pós-Graduação em Psicologia da Universidade Federal do Espírito Santo, Vitória - ES, Brasil E-mail: manu_pagotto@yahoo.com.br

Elisa Fabris de Oliveira

Doutoranda - Pós-Graduação em Psicologia da Universidade Federal do Espírito Santo, Vitória - ES, Brasil Professora da Faculdade de Ensino Superior de Linhares, Linhares - ES, Brasil

E-mail: elisa.fbrs@gmail.com

\section{Edinete Maria Rosa}

Professora - Pós-Graduação em Psicologia da Universidade Federal do Espírito Santo, Vitória - ES, Brasil

E-mail: edineter@gmail.com

Priscilla de Oliveira Martins-Silva

Professora - Pós-Graduação em Psicologia Universidade Federal do Espírito Santo, Vitória - ES, Brasil

E-mail: priscillamartinssilva@gmail.com

\section{Resumo}

A presente pesquisa, de caráter quantitativo, teve como objetivo central conhecer o perfil e a experiência dos jovens em seus espaços de lazer e tempo livre em duas realidades distintas: estudantes de escolas públicas e privadas. Participaram da pesquisa 561 jovens, com idades entre 14 e 19 anos, sendo 291 de 
escolas públicas e 270 de escolas particulares. Como principais resultados, verificou-se uma forte inserção da mídia como forma de ocupar o tempo livre pelos dois grupos investigados, e também uma maior frequência de atividades de lazer realizadas por jovens de escolas particulares. Diante dos resultados, concluiu-se que os contextos sociais, culturais e econômicos acabam influenciando diretamente as experiências desse tempo vivenciado pelos participantes.

Palavras-chave: jovens; tempo livre; lazer; escolas públicas; escolas particulares.

\begin{abstract}
This quantitative research aimed to know the profile and experience of young people in their leisure and free time in two different realities: students from public and private schools. A total of 561 young people, aged 14 to 19 years old, 291 from public schools and 270 from private schools participated in the study. The main results were the strong insertion of the media as a form to occupy free time by the two groups investigated, and also a higher frequency of leisure activities performed by young people from private schools. Given the results, it was concluded that the social, cultural and economic contexts end up directly influencing the experiences of this time lived by the participants.
\end{abstract}

Keywords: youth; free time; leisure; public schools; private schools.

\title{
Resumen
}

La presente investigación de carácter cuantitativo tuvo como objetivo central conocer el perfil y la vivencia de jóvenes en sus espacios de ocio y tiempo libre en dos realidades distintas: alumnos de escuelas públicas y privadas. Participaron de la investigación 561 jovenes, con edades entre 14 y 19 años, siendo 291 de escuelas públicas y 270 de escuelas privadas. Como principales resultados, se evidencia una fuerte inserción de los medios de comunicación como forma de ocupación de su tiempo libre en los dos grupos investigados y también una frecuencia mayor de la realización de actividades de ocio por los jóvenes de las escuelas privadas. Concluyasé que los contextos social, cultural y económico terminan influyendo directamente en las vivencias de ese espacio de tiempo.

Palabras clave: jóvenes; tiempo libre; ócio; escuelas públicas; escuelas privadas.

\section{Introdução}

O Estatuto da Criança e do Adolescente, assim como a Constituição Federal do Brasil (Brasil, 1988), determinam como direito fundamental de qualquer indivíduo, em especial de crianças e adolescentes, o acesso ao lazer. Esse direito, previsto também em âmbito internacional na Declaração Universal dos Direitos Humanos (1948) e reconhecido pela Organização das Nações Unidas (2016), tem devido reconhecimento em virtude de sua direta relação com a saúde física e psíquica dos indivíduos. Já se sabe que são nos momentos de lazer, de livre vivência entre pares, que adolescentes e jovens apreendem as normas sociais, aprimoram o autoconhecimento e estimulam o desenvolvimento de habilidades como a criatividade (Brener, Dayrel \& Carrano, 2008). No entanto, no que consiste de fato o lazer e também o tempo livre? Como jovens de diferentes realidades sociais os têm vivenciado? 
Fatores de risco e de proteção predominam em quais contextos? Essas foram as questões que nortearam a presente pesquisa.

No contexto contemporâneo, se por um lado presenciamos um aumento significativo das opções de lazer, impulsionado, sobretudo, pelos avanços tecnológicos e pela diversidade de experiências a serem consumidas (shows, parques temáticos, cinemas 3D, entre outros); por outro, observa-se que um tempo verdadeiramente "livre" tem se tornado cada vez mais escasso. A separação entre tempo de trabalho e tempo livre tão forte na era pós Revolução Industrial perde força à medida que se estabelece uma cultura do trabalho imaterial (Hardt \& Negri, 2005), do trabalhador que leva "trabalho para casa”, dos contratos flexíveis, dos celulares e notebooks e de relações centradas no meio digital (Biselli, 2006; Navarro, 2006).

Dentro dessa perspectiva e considerando a realidade juvenil - que costuma apresentar menor carga horária de compromisso em relação aos adultos e progressiva autonomia, diferenciando-se das crianças -, o que se percebe é que são eles, os jovens que usufruem de maneira mais significativa dos momentos de lazer e tempo livre. Para Carrano (2003), as relações sociais da juventude se organizam essencialmente "em torno dos gostos, amizades, afetos e relações comuns, cujos centros encontram-se na música, nos espetáculos, nos esportes, nos divertimentos coletivos, nas festas; (...) e cujo eixo é encontrar-se” (p. 149). Assim, para o autor, a maneira de se vestir, a predileção por determinados gêneros musicais e o pertencimento a um grupo funcionam como linguagens através das quais os jovens se identificam e enviam sinais de reconhecimento.

É nesse sentido que muitos autores têm apontado as vivências de lazer e tempo livre dos jovens como dimensões fundamentais para a sua constituição como indivíduos autônomos, sociais e que buscam a formação de identidade(s) e a socialização com seus pares (Coatsworth, Sharp, Palen, Darling, Cumsille \& Marta, 2005; Oliveira, 2006; Brenner, Dayrell \& Carrano, 2008; Miranda, Filho \& Santiago, 2014; Sebenello, Keitel \& Kleba, 2016). O contato com outros jovens que compartilham gostos e interesses semelhantes mostra-se propício não só para a afirmação/reafirmação de laços de amizade, como também para o desenvolvimento da autonomia, protagonismo, criatividade e para a construção de laços de solidariedade e cooperação (Marques, Dell’Aglio \& Sarriera, 2009; Prates, 2012).

Para Franch (2000), são justamente nesses momentos - aparentemente desinteressados - com todos os seus usos, restrições, recriações e regras, que se podem descobrir algumas 
dinâmicas que organizam a vida social dos jovens: estilos de vida, valores, crenças, relações que estabelecem com outros jovens e adultos, enfim, a sua forma particular de estar no mundo.

É relevante ressaltar, contudo, que essas experiências não acontecem de forma universal e homogênea para todos. Compreende-se a juventude como uma categoria socialmente construída, em circunstâncias históricas, econômicas, sociais, políticas e culturais particulares e, logo, os fundamentos de constituição e legitimação de suas práticas de lazer e tempo livre variam de acordo com o contexto social em que os jovens se desenvolvem (Abramo, 2005; Menandro, Trindade \& Almeida, 2010). Variáveis como gênero, etnia, meio em que vivem, grupos com que se relacionam e contexto socioeconômico permitem considerar a existência de diversas juventudes possíveis (por isso a utilização corrente do termo no plural), valorizando suas especificidades e diferenças e rompendo com a ideia de grupo homogêneo com características comuns a uma idade.

No contexto do Brasil, Brenner et al. (2008) consideram que a realidade socioeconômica dos jovens deve ser tomada como chave analítica para entender sua inserção no mundo do lazer. Os autores afirmam que jovens brasileiros ocupam o tempo livre de forma muito variada e sob condições bastante desiguais e alertam que desconsiderar fatores econômicos e sociais em um país onde a diversidade e a desigualdade se fazem fortemente presentes pode ser perigoso. Os estudos de Leão, Dayrell e Reis (2011) e de Zappe e Dell’ Aglio (2016) salientam ainda que são as experiências vividas nessa fase da vida, fortemente determinadas pelo contexto em que se inserem, que vão possibilitar ou dificultar o desenvolvimento de suas potencialidades e projetos de vida.

Investigações como as de Dutra-Thomé, Pereira e Koller (2016), Dutra-Thomé e Koller (2014) e Pfeifer, Martins e Santos (2010) auxiliam a compreender esse contexto. A primeira comparou a relação entre o trabalho e a vida escolar de jovens trabalhadores e não-trabalhadores de várias cidades do país e verificou que os jovens trabalhadores tiveram um engajamento escolar inferior aos jovens que não trabalhavam, além de possuir menos horas de sono e também menos tempo disponível para recreação e lazer, considerada uma importante dimensão para o seu desenvolvimento. A segunda, realizada em Porto Alegre (RS), pesquisou 547 jovens, de classes altas e classes populares, e constatou que os jovens de classes mais altas apresentaram porcentagens significativamente maiores de acesso a ferramentas tecnológicas, tais como: celulares de conta, TV a cabo e acesso a internet em casa e na escola se comparados aos de 
classes mais baixas, o que, para as autoras, acaba ampliando as experiências desses jovens e as possibilidades de se viver em uma sociedade globalizada.

Já o estudo de Pfeifer et al. (2010), com 37 jovens de escola pública e 37 de escola particular, encontrou diferenças significativas em relação ao tempo livre desses alunos ao considerar as variáveis gênero e classe social como recortes, sendo que, as atividades de "leitura” e "uso da internet para pesquisas pessoais” apareceram como mais frequentes entre as meninas de escola particular, enquanto as atividades "namorar/paquerar" e "conversar na internet” apareceram com incidência maior entre as meninas de escola pública.

Diante desse cenário, os estudos recentes sobre o fenômeno têm procurado conhecer e analisar os diversos contextos nos quais os jovens se desenvolvem e, portanto, adota-se nesta pesquisa a busca da identificação dos usos e das interligações das esferas do lazer e do tempo livre entre jovens de duas diferentes realidades: estudantes de escolas públicas e particulares.

No campo teórico, pesquisadores sociais ajudam a compreender a conceituação do lazer e do tempo livre. Na visão de Elias e Dunning (1992), o lazer caracteriza-se por atividades realizadas em uma extensão temporal específica - o tempo livre -, que necessariamente propiciam emoções agradáveis, e que permitem liberação de tensões emocionais acumuladas no dia a dia. Já o tempo livre deve ser entendido a partir de uma concepção temporal, sendo ele propício para diferentes formas de aproveitamento. Nesse sentido, os autores propõem uma classificação de 5 categorias para diferenciar os modos de uso do tempo livre, sendo elas: 1) Trabalho privado e administração familiar; 2) Repouso; 3) Provimento das necessidades biológicas; 4) Sociabilidade; e 5) Atividades miméticas.

A organização dessas categorias foi pensada de acordo com o nível de excitação que as atividades englobadas por elas costumam proporcionar. Assim, a primeira categoria - Trabalho privado e administração familiar - caracteriza-se por ser aquela formada por atividades que não proporcionam excitações, e que, por isso, não poderiam ser entendidas como lazer. A segunda, terceira e quarta categorias - Repouso, Necessidades biológicas e Sociabilidade -, dependendo do modo como as atividades acontecem e de seu contexto, podem proporcionar maior ou menor excitação, mas costumam ficar em um nível mediano. Por último, a categoria das atividades Miméticas ou Jogo é composta pelas atividades que proporcionam maior nível de excitação, rompendo com as rotinas e caracterizando-se por agrupar as atividades essencialmente reconhecidas como lazer (Elias \& Dunning, 1992). 
Ainda sobre a conceituação do lazer e do tempo livre é preciso reconhecer que apesar deles serem uma necessidade intrínseca ao homem, ou seja, em qualquer cultura, sociedade e tempo eles vão se manifestar, a forma como se constituem e são vivenciados varia de acordo com o meio social e histórico, de modo que assumem papéis, nível de importância e tipo de vivência diferente de acordo com o contexto em que são praticados (Elias e Dunning, 1992).

Na sociedade ocidental contemporânea, na qual o espaço público é rigidamente normatizado e o capital e o consumo assumem papéis protagonistas, o lazer e o tempo livre assumem configurações muito específicas e próprias de uma era pós-industrial (Elias, 1994; Dumazedier, 1973). Por outro lado, reconhece-se que para além do macro contexto, as realidades específicas de cada grupo e de cada indivíduo também interferem na vivência e experiência do lazer e do tempo livre, que pode ser, em termos de desenvolvimento humano, melhor ou pior aproveitado.

\section{Materiais e Método}

\section{Participantes}

Participaram da pesquisa 561 jovens, moças e rapazes, com idades de 14 a 19 anos (M= 16,12; DP = 1,07), estudantes de ensino médio, distribuídos em dois grupos: 291 estudantes de escolas públicas (155 do sexo feminino e 136 do sexo masculino) e 270 estudantes de escolas particulares (152 do sexo feminino e 118 do sexo masculino).

\section{Instrumento}

Utilizou-se como instrumento para a coleta de dados a $2^{\mathrm{a}}$ versão do Questionário da Juventude Brasileira (Dell’Aglio, Koller, Cerqueira-Santos \& Colaço, 2011). O questionário originalmente conta com 77 questões relacionadas às temáticas de família, saúde, sexualidade, violência, preconceito, educação e lazer (Dell’Aglio et al., 2011). No entanto, no presente estudo foram utilizados apenas dados referentes a caracterização dos jovens; o acesso a bens tecnológicos e culturais; e as práticas no tempo livre.

\section{Procedimentos}

A coleta de dados aconteceu em dois períodos, em um total de nove instituições escolares, sendo seis da rede pública e três da rede privada, localizadas na Região Metropolitana 
da Grande Vitória, ES. A seleção das escolas públicas se deu de forma aleatória, mediante sorteio e contato prévio com a coordenação de cada instituição sorteada. Em relação às instituições particulares, verificou-se uma forte resistência para a realização da coleta em suas instalações e com seus alunos. Cerca de dez escolas foram contatadas, porém apenas três consentiram em participar da pesquisa. Assim, pela dificuldade da seleção randômica, a amostra assumiu um caráter de conveniência.

Após a autorização das escolas, seguindo todas as diretrizes éticas, os pais dos alunos que concordaram com a participação dos filhos assinaram um Termo de Consentimento Livre e Esclarecido e os jovens voluntários assinaram um Termo de Assentimento. A aplicação do instrumento se deu nas salas, em horário de aula, pelas pesquisadoras e por auxiliares treinados.

As análises estatísticas dos dados coletados foram realizadas com o auxílio do software SPSS. Primeiramente, fez-se uma análise descritiva dos dados, a fim de identificar as características sociodemográficas dos participantes e as frequências de realização das atividades de tempo livre nos dois grupos, bem como, seu acesso a bens tecnológicos e culturais. Em um segundo momento, utilizou-se o teste Qui-quadrado para verificar as possíveis diferenças significativas no uso do tempo livre entre jovens de escolas públicas e particulares e o Teste T de Students para amostras independentes, para verificar relações entre práticas de atividades de lazer e scores nas escalas de Autoestima de Rosenberg (Reppold \& Hutz, 2002) e Perspectivas de Futuro (Gunther \& Gunther, 1998). O nível de significância adotado foi de $\mathrm{p}<0,05$.

\section{Resultados}

Em relação ao perfil sociodemográfico dos participantes, são apresentados os dados referentes às variáveis: renda, composição familiar, escolarização dos pais, cor racial e religião. A Tabela 1 mostra a renda familiar dos jovens de escolas públicas e particulares, medida em salários mínimos. A partir das respostas dos participantes, julgou-se necessária uma categorização diferente dos intervalos de salários considerados para cada grupo. Ressalta-se ainda que foram consideradas nessa questão apenas as respostas válidas dos participantes, visto que a maioria dos jovens nos dois grupos investigados afirmou desconhecer essa informação (Tabela 1). 
Tabela 1. Renda familiar dos jovens em salários mínimos

\begin{tabular}{lccccc}
\hline & \multicolumn{5}{c}{ Porcentagem entre as respostas válidas (\%) } \\
\hline & De 1 a 5 & De 5 a 10 & De 10 a 15 & De 15 a 20 & Mais de \\
\cline { 2 - 6 } $\begin{array}{l}\text { Escolas } \\
\text { Particulares (n=81) }\end{array}$ & 14,8 & 23,5 & 22,2 & 13,6 & 25,9 \\
\cline { 2 - 6 } & Até 1 & De 1 a 3 & De 3 a 5 & Mais de 5 & \\
\cline { 2 - 6 } $\begin{array}{l}\text { Escolas Públicas } \\
(\mathrm{n}=117)\end{array}$ & 6,8 & 49,6 & 29,1 & 14,5 & \\
\hline
\end{tabular}

Observa-se que a maioria dos jovens respondentes de escolas particulares afirmou possuir renda familiar maior que 20 salários mínimos (25,9\%), enquanto nas públicas a porcentagem maior se concentrou na faixa de um a três salários mínimos (49,6\%).

Levando em consideração as outras variáveis analisadas, pode-se dizer que a maioria dos participantes das escolas particulares considera-se branco $(55,4 \%, n=149)$, vive com o pai e com a mãe $(62,6 \%, n=159)$, é católico $(49,6 \%, n=133)$ e o grau de escolaridade dos pais é predominantemente o ensino superior completo $(62,7 \%, n=168)$. Já em relação aos jovens das escolas públicas, a maior parte informou que se considera pardo $(49,8 \%, n=145)$, que vive em um arranjo familiar clássico (48,6\%, N=141), que é evangélico $(43,4 \%, n=126)$ e que os pais possuem ensino médio completo $(59,9 \%, n=167)$.

No que diz respeito ao trabalho, 34,7\% $(n=100)$ dos jovens de escolas públicas afirmaram estar trabalhando, atuando, principalmente, como office-boys, secretárias e profissionais de informática $(n=38)$ ou ainda em comércio, em lojas ou mercados $(n=17)$. Entre os jovens de instituições privadas, esse número é expressivamente menor. Apenas 5,9\% (n=16) dos respondentes afirmaram conciliar a atividade acadêmica com algum tipo de trabalho, sendo a maioria como office-boys, secretárias e profissionais de informática (n=6).

De modo a conhecer os usos do tempo livre entre os jovens investigados, foi perguntado o que costumam fazer quando não estão estudando ou trabalhando, por meio de uma questão de múltipla escolha, com 13 opções de resposta, sendo possível assinalar mais de uma. As tabelas 2 e 3 apresentam as frequências de respostas dos participantes de cada grupo. 
Tabela 2. Frequências e percentuais gerais de respostas por atividades de tempo livre de jovens de escolas públicas

\begin{tabular}{lcccc}
\hline Atividades & $\begin{array}{c}\text { Freq. (N) } \\
\text { Escolas } \\
\text { Públicas }\end{array}$ & $\begin{array}{c}\text { Porcentagem (\%) } \\
\text { Escolas } \\
\text { Públicas }\end{array}$ & $\begin{array}{c}\text { Freq. (N) } \\
\text { Escolas } \\
\text { Particulares }\end{array}$ & $\begin{array}{c}\text { Porcentagem (\%) } \\
\text { Escolas } \\
\text { Particulares }\end{array}$ \\
\hline Navegar na internet & 239 & 84,5 & 244 & 90,4 \\
Assistir TV & 238 & 84,1 & 232 & 85,9 \\
Ouvir ou tocar música & 223 & 78,8 & 223 & 82,6 \\
Descansar & 174 & 61,5 & 203 & 75,2 \\
Cinema ou teatro & 151 & 53,4 & 193 & 71,5 \\
Passear & 150 & 53,0 & 162 & 60,0 \\
Namorar & 142 & 50,2 & 161 & 59,6 \\
Ir a festas & 135 & 47,7 & 152 & 56,3 \\
Ler livros, revistas... & 134 & 47,3 & 143 & 53,0 \\
Praticar esportes & 121 & 42,8 & 136 & 50,4 \\
Jogar/brincar & 107 & 37,8 & 92 & 34,1 \\
Desenhar/pintar/artesanato & 49 & 17,3 & 56 & 20,7 \\
Outros & 25 & 8,8 & 17 & 6,3 \\
\hline
\end{tabular}

As opções "Navegar na internet", "Assistir TV” e "Ouvir ou tocar música” aparecem como as três atividades com maiores frequências de realização tanto entre os estudantes de escolas públicas como os de escolas particulares. Do mesmo modo, como o interesse de lazer menos frequente aparece a atividade "Desenhar/pintar/artesanato".

Utilizou-se o teste do Qui-quadrado para verificar as possíveis diferenças significativas na realização dessas atividades comparando os dois grupos: jovens de escolas públicas e jovens de escolas particulares. Como resultado, observaram-se porcentagens significativamente mais altas para os jovens de escolas particulares nas atividades: "Praticar esportes"; "Jogar/Brincar"; "Ouvir ou tocar música”; "Descansar"; "Navegar na internet”; "Ir a festas"; "Cinema ou teatro"; "Ler livros". Já a atividade "Namorar" foi significativamente mais recorrente entre os jovens de escolas públicas (Tabela 3).

Tabela 3. Frequências e percentuais de atividades de tempo livre significativamente diferentes em relação à escola 


\begin{tabular}{llll}
\hline Atividade & $\begin{array}{c}N(\%) \\
\text { Públicas }\end{array}$ & $\begin{array}{c}N(\%) \\
\text { Particulares }\end{array}$ & \\
\hline Praticar esportes & $121(45,8)$ & $143(54,2)$ & $05,77(1), \mathrm{p}<0,05$ \\
Jogar/Brincar & $107(44,0)$ & $136(56,0)$ & $08,85(1), \mathrm{p}<0,05$ \\
Ouvir/tocar música & $223(49,0)$ & $232(51,0)$ & $05,28(1), \mathrm{p}<0,05$ \\
Descansar & $174(46,2)$ & $203(53,8)$ & $11,95(1), \mathrm{p}<0,05$ \\
Navegar na internet & $239(49,5)$ & $244(50,5)$ & $04,37(1), \mathrm{p}<0,05$ \\
Ir a festas & $135(47,0)$ & $152(53,0)$ & $04,08(1), \mathrm{p}<0,05$ \\
Cinema ou teatro & $151(43,9)$ & $193(56,1)$ & $19,30(1), \mathrm{p}<0,05$ \\
Ler livros, revistas... & $134(45,3)$ & $162(54,7)$ & $08,88(1), \mathrm{p}<0,05$ \\
Namorar & $142(60,7)$ & $92(39,3)$ & $14,67(1), \mathrm{p}<0,05$
\end{tabular}

Em relação ao acesso desses jovens a bens tecnológicos e culturais, tais como acesso à TV por assinatura e internet, observou-se o seguinte cenário: 77,8\% dos jovens de escolas particulares possuem acesso à TV por assinatura, contra 33,9\% dos estudantes de escolas públicas; e o acesso à internet ocorre entre $97 \%$ dos alunos de instituições particulares e 92,8\% entre os jovens do ensino público.

Perguntados sobre a frequência de acesso à internet, 88,1\% dos jovens das escolas particulares e 62,9\% das escolas públicas afirmaram acessar todos os dias. Quanto aos locais de acesso à rede, os jovens de escolas particulares apontaram a casa $(98,5 \%)$ e a escola $(50,7 \%)$ como os principais lugares, apenas 1,1 \% indicou acessar a internet em lan houses, 2,2\% no trabalho e 7\% em algum outro local. Já entre os jovens de escolas públicas esse acesso se dá principalmente em casa $(81,4 \%)$, seguido de lan houses $(18,2 \%)$, escola $(13,5 \%)$, trabalho (12\%) e em outros locais (6,9\%).

$\mathrm{Na}$ análise da relação entre as atividades praticadas no tempo livre e os escores nas escalas de Autoestima e Perspectivas de Futuro, considerando os dois contextos investigados, obteve-se os resultados apresentados nas tabelas 6 e 7. Para alunos de escolas públicas verificou-se que as médias mais elevadas na escala de Autoestima foram encontradas entre os jovens que apontaram as atividades passear, namorar, praticar esportes e ir a festas como suas preferências no tempo livre. Já na escala de Perspectivas de Futuro, os maiores escores foram encontrados entre os jovens que leem livros, namoram e ouvem ou tocam música. (Tabela 4). 
Tabela 4. Médias significativas das atividades de tempo livre a partir das variáveis pessoais.

\begin{tabular}{llllll}
\hline & \multicolumn{2}{c}{ Atividades } & \multicolumn{3}{c}{ Teste t } \\
\hline & Sim & Não & T & Gl & P \\
& M (DP) & M (DP) & & & \\
\hline Autoestima & & & & & \\
$\quad$ Praticar esportes & $4,39(0,61)$ & $4,08(0,71)$ & 3,80 & 279 & 0,05 \\
$\quad$ Passear & $4,30(0,68)$ & $4,11(0,69)$ & 2,32 & 279 & 0,05 \\
$\quad$ Namorar & $4,30(0,64)$ & $4,12(0,72)$ & 2,18 & 279 & 0,05 \\
$\quad$ Ir a festas & $4,33(0,64)$ & $4,09(0,72)$ & 2,95 & 279 & 0,05 \\
& & & & & \\
Perspectivas de futuro & & & & & \\
$\quad$ Ouvir ou tocar música & $4,29(0,57)$ & $4,07(0,57)$ & 2,60 & 278 & 0,05 \\
$\quad$ Namorar & $4,33(0,58)$ & $4,16(0,55)$ & 2,45 & 278 & 0,05 \\
$\quad$ Ler livros... & $4,37(0,49)$ & $4,14(0,63)$ & 3,35 & 278 & 0,05 \\
& & & & & \\
\hline
\end{tabular}

Já para os alunos de escolas particulares, os resultados obtidos demonstraram que os jovens que durante o tempo livre praticam esportes ou jogam/ brincam apresentam médias de autoestima significativamente superiores em comparação com aqueles que realizam essas atividades com menor frequência. Além disso, os escores mais elevados de perspectivas de futuro foram encontrados entre os participantes da amostra que com maior frequência praticam esportes ou namoram. Por outro lado, demonstrando uma relação inversa, foi observado que os jovens que durante o tempo livre mais frequentemente assistem à televisão apresentaram menores médias na escala de perspectivas de futuro (Tabela 5).

Tabela 5. Médias significativas das atividades de tempo livre a partir das variáveis pessoais.

\begin{tabular}{llllll}
\hline & \multicolumn{2}{c}{ Atividades } & \multicolumn{3}{c}{ Teste t } \\
\hline & Sim & Não & T & Gl & P (<) \\
& M (DP) & M (DP) & & & \\
\hline Autoestima & & & & & \\
$\quad$ Praticar esportes & $3,42(0,42)$ & $3,10(0,61)$ & 4,94 & 250 & 0,05 \\
$\quad$ Jogar/ brincar & $3,34(0,51)$ & $3,20(0,57)$ & 2,15 & 250 & 0,05 \\
& & & & & \\
Perspectivas de futuro & & & & & \\
$\quad$ Praticar esportes & & & & \\
$\quad$ Assistir TV & $4,53(0,41)$ & $4,29(0,59)$ & 3,93 & 268 & 0,05 \\
$\quad$ Namorar & $4,39(0,52)$ & $4,56(0,46)$ & $-2,12$ & 268 & 0,05 \\
& $4,53(0,41)$ & $4,36(0,55)$ & 2,76 & 268 & 0,05 \\
\hline
\end{tabular}

\section{Discussão}


Em um panorama geral, os resultados apontam que as três atividades mais realizadas pelos dois grupos investigados são: navegar na internet, assistir TV e ouvir ou tocar música. Essas atividades também aparecem em diversas outras pesquisas que envolvem o tempo livre de jovens em diferentes contextos sociais (Borelli, 2000; Brenner et al., 2008; Marques et al., 2009; Miranda et al., 2014; Passarelli, Junqueira e Angeluci, 2014; Pfeifer et al., 2010; Spizzirri, Wagner, Mosmann \& Armani, 2012).

Ressalta-se que as três atividades apresentam relação direta com os meios de comunicação e a mídia e com muita frequência acontecem de maneira simultânea. Nascidos em uma época de globalização, altamente tecnológica, veloz e integrada, a participação dos jovens em atividades que envolvem produtos midiáticos apresenta-se como o reflexo de uma sociedade que estimula a conexão e a vontade de saber de tudo a todo momento, de seguir as tendências dos estilos de vida propagados e de se distinguir através de bens materiais e simbólicos. Celulares, TVs e internet fazem parte do cotidiano desses jovens e, como destacam Miranda et al. (2014), acabam por cumprir um importante papel de influência na construção de suas identidades. Para os autores, porém, essa relação com a mídia não acontece de forma passiva e os discursos midiáticos, cada vez mais, têm sido influenciados pelos jovens, sobretudo, em uma época marcada pela cultura da participação (Shirky, 2011).

No comparativo entre as atividades realizadas por jovens de escolas públicas e particulares, o que se observa é um cenário bastante desigual. De maneira significativa, os jovens das escolas particulares apresentaram escores mais elevados nas atividades: praticar esportes, jogar/brincar, ouvir música, navegar na internet, ir a festas, ir a cinema/teatro, descansar e ler livros. Estudos como os de Dutra-Thomé et al. (2016) e Dutra-Thomé e Koller (2014) auxiliam a compreender esse dado, ao apontar que jovens de níveis socioeconômicos mais baixos se veem muitas vezes obrigados a se inserir no mercado de trabalho prematuramente, seja para complementar a renda familiar ou em uma perspectiva moral de ocupação do tempo, o que diminui suas possibilidades de usufruir de momentos de lazer. Outro ponto a ser considerado diz respeito a influência do consumo na forma como se usufrui do lazer na contemporaneidade. Vive-se em uma sociedade em que o "ato de comprar" tem se tornado sinônimo de diversão e, cada vez mais, as formas de lazer e entretenimento passam a ser concebidas como serviços a serem adquiridos e consumidos. Nesse sentido, fica claro que é a capacidade de consumo dos jovens e de suas famílias um dos limites mais fortes de sua inserção 
diferenciada no mundo do lazer, que se estabelece como um meio de diferenciação entre os grupos sociais. Assim, quanto mais se pode consumir, mais possibilidades e formas de vivenciar esses momentos se encontram disponíveis (Prates, 2012).

A partir da classificação proposta por Elias e Dunning (1992), observa-se que as atividades miméticas, aquelas que proporcionam maiores níveis de excitação e rompimento da rotina, como, praticar esportes, jogar, ir ao cinema/teatro e festas, são mais realizadas pelos jovens das escolas particulares. Em relação à prática esportiva, o próprio ambiente das escolas particulares mostra-se mais propício para a participação dos jovens: quadras bem equipadas, bolas e até mesmo a presença de “escolinhas” que oferecem diferentes modalidades após o horário convencional de aulas. Em contrapartida, para os jovens de escolas públicas a realidade mostra-se bastante diferente. Em pesquisa anterior sobre a participação de jovens de classes populares em grupos de lazer (Martins 2013), verificou-se que são pouquíssimos ou quase inexistentes os espaços de lazer oferecidos nas escolas públicas ou mesmo em outros espaços das comunidades populares. Os jovens, na maioria dos casos, contam com sua própria força e disposição e improvisam espaços na rua, na falta de locais apropriados. Como afirmam Brenner et al (2008), “nas médias e grandes cidades brasileiras, as periferias, os bairros populares, os morros e as favelas são verdadeiros desertos de equipamentos e instalações culturais (p. 32)”. Assim, outras atividades como ir ao cinema/teatro e ir a festas também acabam ficando muito restritas aos grupos mais privilegiados, já que exigem um maior investimento financeiro e dificilmente são oferecidas em espaços de livre acesso (Dutra-Thomé \& Koller, 2014; Miranda et al., 2014; Sebenello et al., 2016). Nesse sentido, Ortiz (1999) considera que uma importante forma de distinção social entre os indivíduos na sociedade contemporânea é justamente a mobilidade, ou seja, a possibilidade de frequentar os mais diferentes espaços - ir a shows, teatros, restaurantes, viajar de férias, entre outros.

Descansar também aparece como uma atividade com maior frequência de realização entre os jovens das escolas particulares. Dentro da perspectiva de Elias e Dunning (1992), tratase de uma atividade que promove excitações medianas ou nulas e que pode significar repouso ou necessidade biológica. Considerando que esses jovens não apresentam dupla jornada, já que a maioria não trabalha, faz-se necessário entender o que está por trás desse possível cansaço que leva à necessidade de descanso. Acredita-se que uma das explicações esteja no fato de que historicamente, por muitas décadas, o tempo livre esteve diretamente relacionado ao descanso. 
O descansar é entendido, assim como propôs Dumazedier (1979), como reflexo da noção de que o tempo livre deve compensar os esforços realizados no trabalho ou na escola, sendo um momento próprio para o descanso compensatório. Voltando-se aos sujeitos aqui investigados, cabe a reflexão de que apesar de não trabalharem, é comum que os jovens de escolas particulares possuam uma agenda bastante movimentada, com diversas atividades extracurriculares, o que acaba tornando o momento de descanso físico e mental necessário. Em pesquisa anterior sobre representações sociais de tempo livre entre jovens universitárias, o descanso aparece como núcleo central das representações, o que reforça a ideia de que esse tempo é visto como momento compensatório das obrigações cotidianas (Oliveira \& Rosa, 2016).

O namoro é a única atividade que apresentou escores mais significativos entre os jovens de escolas públicas. Dados similares foram observados nas pesquisas de Pfeifer et al. (2010) e Camargo, Abaid e Giacomoni (2011) que encontraram relações significativas entre namoro/relacionamentos e meninas de escolas públicas. É importante ressaltar que as questões relacionadas a namoro e sexualidade passam a despertar significativa atenção dos jovens na faixa etária investigada e as formas de vivenciá-las está bastante relacionada ao contexto em que os jovens se inserem (De Sousa-Mata et al., 2009). O namoro, como pondera Franch (2000), acaba sendo uma atividade de tempo livre bastante comum na vida de jovens de classes mais baixas uma vez que o espectro de opções e oportunidades de vivenciar esse tempo acaba sendo mais escasso e menos estruturado. A pesquisa de De Sousa-Mata et al. (2009), que abordou a gravidez da adolescência, apontou que a maior parte das meninas de classes mais baixas que engravidaram precocemente afirmaram possuir um relacionamento conjugal duradouro com seus parceiros.

Sobre a relação entre os escores nas escalas de Autoestima e Perspecitivas de Futuro, apesar dos resultados terem sido muito diversos, especialmente nos dados com jovens de escolas públicas, chamou atenção o fato de a prática de esportes estar diretamente relacionada aos altos escores nas escalas avaliadas para os estudantes de escolas particulares, possivelmente indicando ser uma prática positiva para o seu desenvolvimento. Por outro lado, o fato de o ato de assistir à TV ter sido a única atividade que apresentou relação negativa entre as variáveis para o segundo grupo de participantes, pode indicar que a sua realização enfraquece a percepção de Perspectiva de Futuro. Apesar de os dados serem preliminares e não indicarem uma relação 
de causa e efeito, entende-se necessário que se questione o excesso de TV na vivência dos jovens e que se reflita sobre a necessidade de disseminação da prática esportiva, maioritariamente realizada entre os jovens de escolas particulares e entre meninos.

No que diz respeito ao acesso dos jovens investigados ao que aqui denominamos como bens tecnológicos e culturais (TV por assinatura, celular pré-pago e pós-pago, internet), os resultados encontrados apontam que a discussão não deve se limitar ao fato de ter ou não ter acesso, mas sim de caminhar cada vez mais para as particularidades como cada grupo consome e se relaciona com esses bens. No caso da internet, por exemplo, estudos recentes demonstram que seu acesso não é uma realidade exclusivamente de jovens de classe média e alta. De acordo com dados da pesquisa TIC Kids Online Brasil 2012, realizada pelo Comitê Gestor da Internet no Brasil, com crianças e jovens de todo o país (Marques, 2013), o que varia entre os indivíduos de diferentes classes é o modo, o local e a frequência de uso, mas grande parte dos adolescentes de classe popular, hoje, também possui acesso a esse a meio.

Voltando-se para as particularidades na posse e uso desses bens, os resultados do presente estudo vão ao encontro dos dados da pesquisa realizada por Dutra-Thomé e Koller (2014). Em ambas, os celulares pós-pagos são mais disseminados entre os jovens de classes mais altas, enquanto entre os de classes populares prevalecem os modelos pré-pagos. Entre as classes mais favorecidas, o acesso a TV por assinatura foi consideravelmente maior e em relação ao acesso a internet, os jovens de classes mais altas alegaram acessar de casa e da escola, enquanto jovens de menor renda acessam de casa e de lan houses.

Para Sarti (2003) é um equívoco considerarmos as camadas populares como classes não consumidoras, definindo-as somente através dos discursos da carência e da falta. Segundo a autora, elas são sim consumidoras, porém participam de outras formas dos circuitos de consumo. Barros (2009) complementa essa ideia ao explicar que muito mais do que simples artefatos tecnológicos, objetos como o computador e o celular possibilitam ao indivíduo de baixa renda inserir-se na sociedade, funcionando como uma espécie de consumo de pertencimento. Vive-se em uma sociedade que exalta o jovem teen de classe média como modelo ideal de juventude (Miranda et al., 2014) e exclui todos aqueles que não se encaixam nesse universo. Celulares, sapatos, roupas, relógios, etc. estão impregnados de status e visibilidade e "os que não se incluem entre os que podem comprar, ficam de fora. Fora da representação. Fora do discurso” (Kehl, 2004, p. 62). Assim, enquanto os jovens de maior renda 
almejam um consumo que os coloque em uma posição de status e exclusividade, o que parece acontecer entre os jovens das classes mais populares é o desenvolvimento de mecanismos adaptados como tentativa de integrar-se a essa sociedade.

Diante do cenário apresentado e apoiando-se nos estudos de Dutra-Thomé et al. (2016), Dutra-Thomé e Koller (2014), Leão et al. (2011) e Zappe e Dell’Aglio (2016), o que se percebe é que para os jovens com melhores condições de vida, as oportunidades para se vivenciar a juventude como um espaço de experimentação e de desenvolvimento de potencialidades acabam sendo maiores do que para os jovens de menor renda. Como explicam Dutra-Thomé et al. (2016), há uma tendência nas sociedades ocidentais industrializadas de que os jovens adiem cada vez mais a adoção de papéis adultos - como a entrada no mercado de trabalho e a formação de uma família - e invistam em sua qualificação e na vivência de experiências diversas. Esse processo, porém, como ressaltam os autores, não ocorre de forma igual em todas as classes sociais e os jovens das camadas populares se veem muitas vezes obrigados a assumir prematuramente as responsabilidades da vida adulta, como trabalhar, casar, morar junto, entre outros. (Dutra-Thomé et al., 2016; Dutra-Thomé e Koller, 2014).

Para Leão et al. (2011) os próprios projetos de vida desses jovens acabam seguindo rumos diferentes, já que estão diretamente relacionados a um campo de possibilidades dado pelo contexto socioeconômico e cultural no qual se encontram inseridos e vivenciam suas experiências. Segundo os autores, no contexto de uma sociedade desigual os jovens, sobretudo os de níveis socioeconômicos mais baixos, defrontam-se com a desigualdade no acesso aos recursos para lidar com o futuro, dificultando-lhes, assim, a elaboração de projetos de vida.

\section{Considerações Finais}

A partir dos resultados obtidos, o presente estudo buscou demonstrar em que aspectos os jovens de escolas públicas e particulares apresentam semelhanças e diferenças entre si, quando analisadas suas vivências de lazer, ocupação do tempo livre e algumas características sociodemográficas. Nesse sentido, observou-se que as atividades diretamente vinculadas à mídia estão no centro de suas ocupações quando se trata de tempo livre e de lazer, mesmo que os modos, o tempo de consumo e as oportunidades de acesso variem de um grupo para outro.

No entanto, não se pode deixar de pontuar as divergências encontradas. Verificou-se que a frequência de realização das atividades de lazer, para quase todas as alternativas 
analisadas, é significativamente maior para os alunos de escolas particulares. Claramente, o contexto social e econômico demonstraram privilegiar para esses jovens a prática de esportes; o jogar e o brincar; atividades relacionadas à música; a navegação na internet; a leitura de livros; e a ida a festas e ao cinema/teatro. Sendo essas atividades essencialmente caracterizadas como miméticas (Elias \& Dunning, 1992) e tendo os resultados demonstrado relação entre elas e os altos escores nas escalas de Autoestima e Perspectivas de Futuro, entende-se que a sua realização pode estar relacionada ao melhor aproveitamento do lazer e do tempo livre e que a desigualdade contextual observada precisa ser superada.

Acredita-se ser fundamental que se questione se a falta das atividades miméticas, desenvolvidas principalmente como forma de socialização, de desenvolvimento de habilidades artísticas e esportivas e de autoconhecimento, não poderia estar prejudicando o estímulo do desenvolvimento saudável desses jovens e a elaboração de seus projetos de vida. Cada vez mais a importância das atividades de lazer e da boa vivência do tempo livre para o desenvolvimento juvenil tem sido reconhecidas, e, assim, entende-se que essa discrepância entre os jovens de escolas públicas e particulares seja um fator que exija intervenção. Nesse sentido, também fazse necessário pontuar que essas as limitações de acesso ao lazer, possivelmente ferem ou ao menos prejudicam o direito previsto aos jovens e a todos os cidadãos na Declaração Universal dos Direitos Humanos (1948) e na Constituição Federal do Brasil (1988).

Deve-se, contudo, estar a tento ao fato de que a restrição de acesso, seja ela a equipamentos tecnológicos, a atividades extracurriculares e culturais e a espaços físicos, talvez não seja o único dificultador para as vivências dos jovens de escolas públicas. $\mathrm{O}$ fato de eles estarem em maior número atuando no mercado de trabalho, reduzindo, assim, a extensão temporal passível de ser dedicada ao lazer, também é um ponto a ser considerado.

Por outro lado, é curioso notar que mesmo sendo os jovens de escolas públicas os que mais trabalham, o descansar como uma ocupação de tempo livre aparece com maior frequência entre os jovens de escolas particulares. Esse dado está diretamente relacionado a representação social de tempo livre para os estudantes de escolas particulares, mas é preciso que se verifique se outros fatores também não estariam atuando nessa configuração. Além disso, investigar sobre as consequências desse descanso, muitas vezes traduzido em horas dormidas durante tardes inteiras, também seja de suma importância. 
Como limites da pesquisa, ressalta-se o fato de seu recorte ter possibilitado a verificação dos modos de ocupação do tempo livre e de vivências de lazer, mas de não ser capaz de responder a questões sobre seus efeitos. Além disso, entende-se que o estudo, apesar de contemplar uma amostra significativa e representativa, abarca apenas uma realidade limitada, referente a estudantes de escolas públicas e particulares localizadas na cidade de Vitória - ES. Assim, entende-se que a continuação das investigações, possibilitando a complementariedade dos resultados até então obtidos, seja fundamental para que se possa entender a realidade social e de lazer dos jovens brasileiros, e para que se busque aprimorar o aproveitamento desse tempo, considerando as diferenças envolvidas em cada contexto.

\section{Referências}

Abramo, H. W. (2005). Condição juvenil no Brasil contemporâneo. In. H. W. Abramo, \& P. P. M. Branco (Eds.), Retratos da juventude brasileira: análises de uma pesquisa nacional (pp. 37-72). São Paulo: Fundação Perseu Abramo.

Barros, C. F. P. (2009). Apropriação de tecnologias digitais e usos de celulares nas camadas populares. In Congresso Brasileiro de Sociologia (Ed.), Anais - CD-ROM. Rio de Janeiro: Sociedade Brasileira de Sociologia.

Brasil. Constituição (1988). Constituição da República Federativa do Brasil. Brasília: Senado.

Biselli, A. M. F. (2006). Lazer de uma juventude socialmente vulnerável na cidade de São Paulo. Dissertação de mestrado, Fundação Getúlio Vargas, São Paulo, SP, Brasil.

Borelli, S. H. S. (2000). Jovens em São Paulo: Lazer, consumo cultural e hábitos de ver TV. Nómadas, 13, 92-97.

Brenner, A. K, Dayrell, J., \& Carrano, P. (2008). Juventude brasileira: culturas do lazer e do tempo livre. In Teles, N. (Org.) Um olhar sobre o jovem no Brasil (pp. 29-44). Brasília: Editora do Ministério da Saúde.

Camargo, S. P., Abaid, J. L., \& Giacomoni, C. H. (2011). Do que eles precisam para serem felizes? A felicidade na visão de adolescentes. Revista Semestral da Associação Brasileira de Psicologia Escolar e Educacional, 15(2), 241-250.

Carrano, P. C. R. (2003). Juventudes e cidades educadoras. Rio de Janeiro: Vozes.

Coatsworth, J. D., Sharp, E. H., Palen, L. Darling, N., Cumsille, P.,\& Marta, E. (2005). Exploring adolescent self-defining leisure activities and identify experiences across three countries. International Journal of Behavioral Development, 29 (5), 361-370. 
Declaração Universal dos Direitos Humanos (1948). Assembleia Geral das Nações Unidas em Paris. In: http://www.ohchr.org/EN/UDHR/Documents/UDHR Translations/por.pdf

Dell’Aglio, D. D., Koller, S. H., Cerqueira-Santos, E., \& Colaço, V. F. R. (2011). Revisando o questionário da juventude brasileira: uma nova proposta. In D. D. Dell'Aglio \& S. H. Koller (Eds.), Adolescência e juventude: vulnerabilidade e contextos de proteção (pp. 260269). São Paulo: Casa do psicólogo.

De Sousa-Mata, A. N., Araújo-Lemos, C., Lira-Ferreira, C., Pereira-Braga, L., \& Chaves-Maia, E. M. (2009). Fatores de risco na repetição de gravidez na adolescência. Rev. Col. Psic., 18(2), 167-175.

Dumazedier, J. (1973). Lazer e cultura popular. São Paulo, SP: Perspectiva.

Dumazedier, J. (1979). Sociologia empírica do lazer. São Paulo: Perspectiva.

Dutra-Thomé, L., \& Koller, S. (2014). Emerging Adulthood in Brazilians of Differing Socioeconomic Status: Transition to Adulthood. Paidéia (Ribeirão Preto), 24(59), 313322.

Dutra-Thomé, L., Pereira, A. S., \& Koller, S. H. (2016). O desafio de conciliar trabalho e escola: características sociodemográficas de jovens trabalhadores e não-trabalhadores. Psicologia: Teoria e Pesquisa, 32(1), 101-109.

Elias, N. (1994). O processo civilizador: Uma história dos costumes. Rio de Janeiro: Zahar.

Elias, N., \& Dunning, E. (1992). A busca da excitação. Lisboa: Difel.

Franch, M. (2000). Tardes ao léu: um ensaio etnográfico sobre o tempo livre entre jovens de periferia. Dissertação de Mestrado, Universidade Federal de Pernambuco, Recife, PE, Brasil.

Gunther, I. A. \& Gunther, H. (1998).Brasílias pobres, Brasílias ricas: perspectivas de futuro entre adolescentes. Psicologia: Reflexão e Crítica, 11(2), 01-11.

Hardt, M., \& Negri, A. (2005). Multidão: guerra e democracia na era do império. Rio de Janeiro: Record.

Kehl, M. R. (2004). O espetáculo como meio de subjetivação. In E. Bucci e M. R. Kehl (Eds.), Videologias: ensaios sobre televisão (pp. 42-62). São Paulo: Boitempo.

Leão, G.; Dayrell, J., \& Reis, J. (2011). Juventude, projetos de vida e ensino médio. Educação \& Sociedade, 32 (117), 1067-1084.

Marques, J. A. (2013). Usos e apropriações da internet por crianças e adolescentes. In Barbosa, A. F. (Coord.). Tic kids online Brasil 2012: Pesquisa sobre o uso da internet por crianças e adolescentes no Brasil (pp. 55-64). São Paulo: Comitê Gestor de Internet no Brasil. 
Marques, L. F., Dell’Aglio, D. D., \& Sarriera, J. (2009). O tempo livre na juventude brasileira. In R. M. C. Libório, \& S. H. Koller (Eds.), Adolescência e juventude: risco e proteção na realidade brasileira (pp. 79-106). São Paulo: Casa do psicólogo.

Martins, M. P. (2013). Tempo livre da juventude de classe popular: desatando preconceitos e promovendo perspectivas positivas. Dissertação de Mestrado, Programa de Pós-Graduação em Psicologia, Universidade Federal do Espírito Santo, Vitória.

Menandro, M. C., Trindade, Z. A., \& Almeida, A. M. (2010). Gente jovem reunida: Representações sociais de adolescência/juventude em textos jornalísticos. Vitória: PPGP/UFES.

Miranda, L. L., Filho, J. A., \& Santiago, M. V. (2014). A relação lazer e mídia entre adolescentes e jovens de escolas públicas em Fortaleza/CE. Psicologia Argumento, 32(79), 29-43.

Munné, F. \& Codina, N. (1992). Algunos aspectos del impacto tecnológico en el consumo infatil del ocio. Anuario de Psicología, 53 (2), 113-125.

Munné, F. \& Codina, N. (2002). Ocio y tempo libre: Consideraciones desde uma perspectiva psicossocial. Revista Licere, 5(1), 59-72.

Navarro, V. L. (2006). Trabalho, saúde e tempo livre sob os domínios do capital. In V. Padilha (Ed.), Dialética do lazer (pp. 50-74). São Paulo: Cortez.

Oliveira, E. F. \& Rosa, E. M. (2016). Representações sociais de lazer e de tempo livre: vivências e sociabilidades de jovens universitárias. Psicologia e Saber Social, 5(1), 46-67.

Oliveira, M. C. S. L. (2006). Identidade, narrativa e desenvolvimento na adolescência: Uma revisão crítica. Psicologia em Estudo, 11(2), 427-436.

Organização das Nações Unidas (2006). Declaração Universal dos Direitos Humanos. In: http://www.dudh.org.br/declaracao/

Ortiz, R. (1999). Mundialização e cultura. São Paulo: Brasiliense.

Passarelli, B., Junqueira, A. H., \& Angeluci, A. C. B. (2014). Os nativos digitais no Brasil e seus comportamentos diante das telas. Matrizes, 8(1), 159-178.

Pfeifer, L. I., Martins, Y. D., \& Santos, J. L. (2010). A influência socioeconômica e de gênero no lazer de adolescentes. Psicologia: teoria e pesquisa, 26(3), 427-432.

Prates, M. A. (2012). Conhecer, explorar e desenvolver atividades para o tempo livre: um jeito próprio de ver a vida. In J. C. Sarriera, \& A. C. Paradiso (Eds.), Tempo livre e lazer na adolescência: promoção de saúde, intervenção e pesquisa (pp. 61-95). Porto Alegre: Sulina. 
Reppold, C. T. \& Hutz, C. (2002). Auto-estima entre adolescentes de uma amostra não clínica: Prevalência, fatores influentes e subsídios para intervenção [Resumo]. Em Fórum de Entidades Nacionais da Psicologia Brasileira (Org), Resumo/ Abstract, I Congresso Brasileiro Psicologia: Ciência e Profissão, (p 89). São Paulo: SP.

Sarti, C. A. (2003). A família como espelho: um estudo sobre a moral dos pobres. São Paulo: Cortez.

Sebenello, D. C., Keitel, L., \& Kleba, M. E. (2016). Práticas de lazer e espaços públicos de convivência como potência protetiva na relação entre juventude e risco. Revista Katálysis, 19(1), 53-63.

Spizzirri, R. C., Wagner, A., Mosmann, C. P., \& Armani, A. B. (2012). Adolescência conectada: mapeando o uso da internet em jovens internautas. Psicologia Argumento, 30(69), 327-335.

Zappe, J. G. \& Dalbosco Dell’Aglio, D. (2016). Risco e proteção no desenvolvimento de adolescentes que vivem em diferentes contextos: Família e institucionalização. Rev. Col. Psic., 25(2), 289-305. 